\title{
ИСТОРИЧЕСКИЕ ФОРМЫ ГАРМОНИЗАЦИИ ЧЕЛОВЕЧЕСКОЙ ЖИЗНИ
}

\section{И.В. Шевченко}

Современный этап развития философии характеризуется возрастанием роли ее практической функции, когда философия не столько объясняет бытие сущего, сколько ищет способы и формы, ставит задачи воплощения различных идей в действительность. В этой связи трансцендентальную идею жизнебытийного порядка (гармонии) можно представить как основание смысла актуального жизнеустроения отдельного человека, социальных групп, общества в целом.

Свое реальное воплощение в человеческом бытии гармония может иметь в таких объективациях и жизненных проективностях, интегрированное единство которых составляет вариативность жизненных миров, их конструирование и реконструирование по законам гармонии. Жизненный мир, в таком понимании, предстает организующим началом, связующим звеном и необходимым аккумулятивно-трансляционный компонентом взаимодействий и взаимоотношений универсального личностного и общечеловеческого миропорядка. В «снятом» виде как реальный, конкретный мир жизни человека, жизненный мир каждый раз являет собой бесконечную смысложизненную интерпретацию бытия социокультурных норм, идей, идеалов, ценностей.

Данное положение очерчивает «бытийность» жизненного мира в качестве мира определенной социокультурной целостности как «мира жизненной культуры». Мир жизненной культуры-это мир представлений субъектов жизнетворения и жизнеустроения о проективности и воплощении целей, ценностей, идеалов, значений и смыслов культуры в модификациях жизненных миров и жизни как гармонической целостности [13]. Соответственно, логика упорядочения бытия

Актуальні проблеми духовності 
людей есть логика созидания мира жизненной культуры как новой ценностно-культурной жизненной реальности, логика созидания новых оснований, возможностей, форм и способов устроения жизненных миров. Следовательно, конкретно-исторические формы гармонизации жизненных миров определяются системой ценностей конкретно-исторической формы мира жизненной культуры как духовной гармонии (духовной атмосферы) социума и духовной гармонии внутреннего духовного мира личности.

Исходя из вышеизложенного, можно предположить теоретические инварианты (модели) жизненных миров и жизненных культур различных культурно-исторических эпох, их жизнеустроительные детерминации и бытийные основания, уникальность и неповторимость которых определяется многообразием социальных «идеалов» «различных способов тематизации реальности» (Э.Гуссерль) в мире жизненной культуры, отрефлектированных в религиях, мифологемах, философских идеях, искусстве и т. п. как констант упорядочения, устроения, организации и согласования человеческого жизнетворения.

Так, для архаичных жизненных миров человека основанием упорядочения жизни были обычаи и традиции. К примеру, в древнем Китае и Индии гармония человеческого «Я» традиционно рассматривается в корреляции с универсальной духовной субстанцией, небом и их земными репрезентантами. Тем не менее, уже в древнегреческой модели жизненного мира намечается своего рода «превращенная социология» (Н. Мотрошилова) как единство макро- и микрокосмоса, предполагающее диалектическую взаимосвязь и взаимодействие, диалогику материального и духовного, личностного и полисного, объективного и субъективного.

Жизнетворение средневекового человека изначально гармонично, если оно осуществляется в «союзе» с Богом. Если же это «союз» человека и Дьявола, то и жизненный мир, и жизнетворение приобретают антиподный первому варианту характер, что и предопределяет, замечает В.Лутай, «трагедию выбора» человека и, одновременно, «сложную проблему» осмысления жизнеустроения человека христианской теологией и религиозной философией $[7$, с.68].

Таким образом, социальная гармония средневекового человека и общества достигалась с помощью неоспоримых и обязательных для всех сословий норм поведения, имеющих божественный статус. Однако такая гармония потенциально всегда содержит момент дисгармонии, проявляющейся в формах жизни, поступках и поведении людей, несоответствующих традиционной «схеме» как априори репрезентиру- 
ющих гармоничность человеческого бытия. Отражение этих «непредустановленных» дифференциаций жизни в общественном сознании конституировало изменение и закрепление несколько иной социальной структуры общества и соответствующих им религиозно-духовных и культурных образований, выполняющих регулятивно-организационную функцию упорядочения жизненного мира средневекового человека и общества.

Иными словами, деятельность церкви становилась фактором стабилизации, упорядочивания жизненного мира средневековья. Подменяющая государство и право, она при этом руководствовалась «кнутом» и «пряником» - инквизицией, христианской моралью и добродетелями. Следовательно, присутствовавшая в социальных отношениях и жизни людей средневекового общества «невидимая суть» - абсолют (гармония) как бы создавала стабильный фон жизненного мира с духовным и моральным ценностным содержанием, нормативной этикой социального и экзистенциального поведения, искусством и культурой.

Тем не менее, в такой организации жизни можно обнаружить и крайне полярные жизненные миры - «горний» и «дольный» [1, с. 184], разные формы осуществления человеческого жизнетворения - «официальную» и «карнавально-площадную» [2, с. 220], наконец, разные формы человеческого самоопределения - «внешнего человека» и «человека внутреннего» [1, с. 132]. Отсюда две «культуры»-культура духа и культура тела, быта, сакральная и секулярная; два вида «любви» - эгоистическая к себе и бескорыстная к Богу [1, с. 82], две «музыки»- «музыка сфер, ставшая музыкой души» и «музыка суетного мира» $[11$, с. 224], две «красоты», две «воли» $[1$, с. 103] и т. п.

Вариативность этой стилистики жизни отразила барокковая культура с ее экспрессией и театрализованностью, раскрепощающей сущностные силы человека, его жизнетворчество и заменившая образность, символизм жизнебытийного самовыражения человека Средневековой культуры смыслом, значением. «Указующий палец символически устремлен ввысь, в небо,-за пределы земных предметов и, одновременно, - вглубь, в предмет, в его собственное точечное, «ничтожное» (дисгармоничное - И. ШІ.) бытие», - подчеркивает В.Библер [11, с. 249]. Вполне понятно, что такая культурная биполяризация порождала определенный социально-психологический эффект - социокультурное и духовное раздвоение общественного сознания и деятельности, означающее устремленность мира жизненной культуры человека и социума к смене модели жизненного мира, стиля и образа жизни.

Жизненный мир и мир жизненной культуры Возрождения репре- 
зентован так называемой «классической» моделью человеческого жизнеустроения, согласно которой жизнебытийность человека есть проявление его специфической природы - разумной деятельности. Наделенный разумом человек способен действовать не как природное тело или «инструмент» в руках Творца, а как самодостаточный субъект жизнетворения. Таким образом, в свете этой модели, разумная творческая деятельность дает человеку возможность не подчиняться природной и фатальной необходимости, а действовать согласно со своими рационально осознанными целями, то есть свободно, определяя себя центром мироздания, а не только своего жизненного мира.

Поэтому «идеологию» жизненного мира - мир жизненной культуры Возрождения называют гуманизмом, понимая под этим «открытие человека» как свободного и неограниченного в своих возможностях субъекта жизнетворения, постепенно освобождая его из плена религиозной компетенции и теологических санкций и возводя в ранг высшей мировоззренческой и жизненной ценности. В связи с этим пересматриваются взгляды и на социум. Осуществляются первые попытки идеологического и теоретического обоснования идеи гражданского общества, появляются политическая доктрина Н. Макиавелли, теория права Ж. Бодена, социологические утопии Т. Мора, Т. Кампанеллы и др., отражающих зависимость процесса упорядочения человеческой жизни от идеалов и ценностей нового мира жизненной культуры, формирующей новую духовную атмосферу общества.

Таким образом, разум, сознание, свободная творческая деятельность индивида, личности, с одной стороны, и гражданственность, гуманизм социума, с другой, выступают основополагающими гармонизирующими детерминантами организации жизненного мира и жизненной культуры Возрождения. Их же общий смысл и значение детерминированы жизнеустроительной логикой творческого субъекта - миром собственных человеческих целей, смыслов, потребностей, интересов и возможностей. Вместе с тем, уже в эпоху Возрождения становится очевидным, что оценка человеческого жизнетворения как результата разумной деятельности не адекватна действительности. Видимо поэтому некоторые представители этого времени, в частности М. Монтень, ищут образцы гармонической жизнеустроительной парадигмы не среди современников, а в обычаях древних греков.

Новое время, продолжая антропоцентристские традиции Возрождения, выстраивает картину жизненного мира человека и социума в соответствии с тенденциями дифференциации, интеграции и универсализации. Соотнесение таких глубинных понятий человеческого бытия 
как жизнь и смерть, «свое» и «чужое», «мой дом» и «мироздание» чаще всего анализируются наукой, философией, искусством, теологией. Они репрезентуют как определенную целостность общественного сознания, его единство, основанное на традиционном понимании социальных норм, долга и обязанностей, так и его рассогласованность, отражая внутренние противоречия самого Нового времени и места человека в нем. «Индустриальные» условия жизни приобретают качество реальности для человека, предстают жизненно важными. Таким образом, в мире жизненной культуры человека и социума Нового времени понятие «разум» становится тождественным понятию гармонии.

Поэтому, жизнь человека и социума XVIII в. - это разумно устроенный театр, где у каждого своя роль, а видимость целостности (гармонии) - сцена. Разумно устроенному же жизненному «театру» противопоставляется «антитеатр» с соответствующими разуму техниками господства и подчинения. «Жиизенный театр» господ, как разумно устроенный жизненный мир и мир жизненной культуры, и «антитеатр» бедноты, как всего лишь мир здравого смысла, тем не менее нуждались друг в друге и, разыгрывая между собой «впечатляющее» жизненное «шоу» [5, с. 188], способствовали сохранению определенного социального равновесия. Однако, одновременно с существованием социального консерватизма, защищавшего прежние нормы, традиции и опиравшегося на здравый смысл, в XVIII веке утверждалась новая система ценностей, сердцевиной которой становится господство человека над человеком, искривленное и отчужденное бытие, понимаемое фактически как его небытие.

Не случайно именно в это время становится весьма содержательным понятие отчуждения (Г.Гегель) в мире жизненной культуры и духовной жизни человека и социума, олицетворяющее иную модальность гармоничности, ее потенциальность и возможность превращения в действительность путем разрешения противоречий человеческой жизнеустроительности. Учитывая же современные реалии, отчуждение и деструкция все более и более приобретают характер тотальных, проявляясь в жизни в таких модальностях дисгармонии как «гармонической», «гармонизированной» всеобщности отчуждения, различных формах ее «негармонической гармоничности», «гармонической негармоничности», «неустойчивого равновесия» и пр. Многочисленные социальные структуры и институции вместо того, чтобы нести компенсаторные свойства по нейтрализации саморазрушения жизненного мира человека путем его поддержки социокультурной системой ценностей и смыслов, чаще всего не выполняют эти функции, провоцируя, тем са- 
мым, по образному выражению А.Панарина, ситуацию «отложенной нравственности» [9, с.16]. В подобных ситуациях теряется реальная возможность реализации жизнетворения, подвергается сомнению осознание значимости и смысла гармонизирующих детерминант, форм и способов, содержательный и ценностный потенциал человеческой жизнеустроительности.

Вместе с тем, как феномен социальное отчуждение сложное, противоречивое и неоднозначное явление. Прежде всего, это исторически закономерный и объективный процесс развертывания человеческого жизнетворения, источник и результат превращения относительного олицетворения характера взаимоотношений человеческих индивидов с социумом как некоей «самостоятельной силы, господствующей над ним» $[12$, с. 472$]$.

Преломляясь в социальном жизненном мире и «сознании индивида (разрыв между ожиданиями, желаниями человека и нормами, предписываемыми социальными структурами, восприятие этих норм как чужих и враждебных личности, чувство изоляции, одиночества, paзрушения норм поведения и т. п.)» [12, с.472], отчуждение становится в то же время узлом жизненных устремлений человека и социума, накладывая свой отпечаток на человеческую деятельность, культуру, воспитание, искусство и жизнетворение. То есть, оно может иметь такие формы сознания и самосознания, в основе которых лежит переориентация системы человеческих отношений, связей, оснований и смыслов жизнетворения на выбор сознательного варианта бытия как особой формы жизнеустроения человека.

Вспомним «отшельничество», исихазм и различные коллективные формы «самостояния», как то: Н. Сорский и А.Рублев, пифагорейская школа и Академия Платона, музыкальная школа пения Гвидо из Ареццо и итальянская (креонская) скрипичная школа А. Амати и Н.Амати, Д. Гварнери и А.Страдивари, Киево-Могилянская академия, философское и культурное движение «шестидесятников» ХX ст. и мн.др. Всех их отличало неприятие утративших смысл и актуальность жизнеустроительных детерминант, устремленность к нравственному и духовному совершенствованию своего бытия. Ибо, как замечает Э.Фромм, при любой форме отчуждения, в том числе и тотального, человеку всегда предоставлено право выбора между «быть» и «иметь», базирующееся на принципе здравого смысла «может-бытьи-иначе». Причем, чем больше этот принцип содержит в себе иного, отличного от того, что есть, тем больший простор выбора, а значит и свободы жизненного переустройства. Этот выбор, прежде всего, цен- 
ностный и целевой (деятельностный), это мир человеческих поступков и решений, учета необходимости и возможности конструирования нового жизненного мира и мира жизненной культуры в поликультурном пространстве социальных и экзистенциальных коммуникаций.

Такова жизненная культура тоталитарных обществ. Ее «силовое поле» (Э. Томпсон) вместо конструктивной функции утверждает противостояние социальных групп людей с различными потребностями, интересами и целями, по-разному определяющими смысл и свое предназначение в жизни, что, в конечном счете, выражается в трансформациях жизненного мира и мира жизненной культуры. Более того, в «диарамме социального напряжения» [5, с. 182] все феномены становятся «мятежными» в борьбе традиционного и нового в жизнеустроении человека и социума. Консерватизм и инновации приобретают форму видимых конфликтов и конфронтаций, содержанием которых становится распад старой, трансформация и становление новой системы ценностей, смена мира жизненной культуры как духовного основания социокультурного бытия людей. Последнее обусловливает изменение социальной позиции, форм и способов жизнедеятельности субъектов жизнетворения.

Жизнетворение в условиях современного (индустриального и постиндустриального) общества - качественно новый, динамический тип социокультурного опыта. Он сложился в промышленно развитых странах и имеет свои особенности и черты. Во-первых, высокий уровень адаптивности человека к данной социокультурной ситуации как сущему, обеспечивающей его относительно стабильное существование своей структурной устойчивостью, высоким уровнем специализации экономических, политических, социальных и культурных институций и четкой дифференциацией их функций. Во-вторых, способность социальных механизмов гибко реагировать на возникающие жизнебытийные кризисы и конфликтные ситуации с помощью такого «инструментария» упорядочивания, разрешения социокультурных проблем и всего спектра взаимоотношений человека, мира и общества как консенсус [4, c. 46], а не только насилие и принуждение.

Тем не менее, весьма и весьма проблематично утверждать однозначно, что модель жизненного мира современного человека-полная и абсолютная противоположность исторически предшествующим. Основанием данного скепсиса служит ценностная ориентация современного человека в процессе жизнеустроения, проявляющая утрату и трансформацию многих общезначимых ценностей и смыслов человеческой жизнебытийности. Видимо поэтому в жизни современного человека со- 
вершенно закономерно присутствуют ностальгия, внутренняя напряженность, беспокойство, поскольку определяющей ее ценностью становится не «быть», а «иметь» и время жизни определяется «временем денег». Но возвращение к прежней культуре невозможно. Следовательно, человек должен вновь «учиться» искусству жить, соединив элементы старой и новой культуры в новом синтезе, ориентированном на потребности и цели «нового» человека и «нового» общества, пережив «культурный шок» в процессе собственного жизнеустроения.

В современной культурологии (М. Коуэл, Э. Тоффлер, П. Козловски) «культурошок» рассматривается как восприятие современного состояния мира жизненной культуры неподготовленным человеком к облику абсурдной «испорченности» культуры, когда культурные формы теряют общечеловеческие смыслы и значения, составляя социальный и экзистенциальный жизнебытийный «псевдоконтекст, в котором отсутствует содержание» [6, с.215]. «Отражаясь» в коллективном сознании и превращаясь в антисозидательную и асоциальную силу, они угрожают человеку, с одной стороны, ориентацией на неадекватное восприятие реальности, его обращение к мифотворчеству в конституировании и конструировании жизненного мира. С другой,-лишением возможности жизнебытийной адаптации новым неизвестным формам жизни в случае исчезновения привычных и проверенных жизнью форм. Подобная психологическая дисгармония понижает активность и жизненный тонус человека. Он начинает комплексовать, теряться, впадать в беспокойство в процессе жизнеустроения. Тем более, что состояние «трансцессии» (Э. Тоффлер) современной темпоральности жизни, придает субъектам жизнетворения черты непостоянства, обеспокоенности дискретностью жизненного мира, вследствие чего содержание их мира жизненной культуры все больше и больше девальвируется, конституируя тем самым не гармоническую жизнебытийность человека и социума, а жизнь как «иерархию допустимого», «наименьшего зла», о чем пишет Л. Карасев [10, с. 16].

Вместе с тем, задаваясь вопросом: «что есть человек и его бытие как целостность?» С. Кьеркегор, Г. Сковорода, П. Юркевич, М. Шелер, М.Бубер и др. наиболее значимыми для пробуждения человеческой жизнетворческой позитивности, целе- и смыслосообразности полагали духовные чувства. Благодаря им «человек со всей необратимостью предстает как вопрос для самого себя, как проблема жизни», - подчеркивал М. Бубер [3, с. 164]. Поскольку лишь оставшись наедине с собой и своими бытийными проблемами, он встречается с собственным «Я», со способностью «соотносить себя с абсолютным моральным образ- 
цом» $[8$, с. 77-78], в основе которого лежит целе- и смыслосообразная жизнетворческая сущность человека.

Любой же сознательно выбранный человеком и социумом вариант жизнетворения есть «движение от будущего недействительного к действительно истинному» (А. Маслоу), что актуализирует верификацию целевых и смысло-ценностных ориентиров, наличие о-смысленных манифестаций, творческих усилий и морально-нравственных ограничений в процессе гармонического жизнеустроения. Именно в его фокусе - аксиологическая оценка человеком своих поступков, что особенно важно для сохранения человечности, самосовершенствования и развития личности, поскольку не исключает, а, напротив, предполагает добровольное самоотстранение и самоотречение во имя получения внутренней свободы и достойных человека (культурных, духовных) способов жизнетворения.

Вместе с тем, не следует забывать, что самоактуализация может иметь и негативный оттенок. Особенно в случае, когда индивидом игнорируются социальные идеалы, цели и смыслы, общекультурные ценности и архетипы созидания, когда разрушаются связи между внутренними и внешними обстоятельствами, не совпадают потребности человека с возможностями их удовлетворения. C другой стороны, законные ожидания и жизненно оправданные намерения личности не могут быть индифферентными для социума, поскольку, как и в первом случае, постулируется негативная жизнеустроительная креативность субъектов жизнетворения, неадекватность мира жизненной культуры и жизненного мира целям и возможностям личности, ее инновационным жизненным устремлениям.

Таким образом, устроение человеческой жизни конституируется принципом и законами социокультурной гармонии, поскольку снятие различных форм «негармонической жизненной гармоничности», «гармонизированной негармоничности», «неустойчивого жизненного равновесия» иным путем невозможно без сокрушительных потрясений и драм в человеческой жизнебытийности. Следовательно, в зависимости от отношений, которые складываются в реальном взаимодействии между людьми, индивидом и обществом, личностью, социумом и культурой находится позитивная или негативная конституэнта человеческого жизнетворения. Она либо наполняет жизненный мир субъектов жизнетворения пессимизмом и крахом надежд, потерей смысла бытия, либо оптимизирует, мотивирует и стимулирует их жизнетворческую субстанциальность адекватными формами - жизненной культурой и духовностью личности и социума. 


\section{1 Литература}

[1] Августин Аврелий. Исповедь.- М.: Республика, 1992.

[2] Бахтин М.М. Проблемы поэтики Достоевского.-3-е изд. - М.: Художественная литература, 1972.

[3] Бубер М. Два образа веры: Пер. с нем.-М.: Республика, 1995.

[4] Горбатенко В. У смисловому полі модернізаційного дискурсу // Філософська думка, 1999. - № 4.- С. 35-56.

[5] История ментальностей, историческая антропология. Зарубежные исследования в обзорах и рефератах. - М.: Российский гос. гуманитарный ун-т, 1996.

[6] Козловски П. Культура постмодерна. - М.: Республика, 1997.

[7] Лутай В.С. Філософія сучасної освіти: Навч. посібник. - К.: Центр «Магістр-S» Творчої спілки вчителів України, 1996.

[8] Мировоззренческая культура личности (Философские проблемы формирования (В.П.Иванов, Е.К. Быстрицкий, Н.Ф.Тарасенко, В.П. Козловский (Отв.ред. В.П.Иванов. - К.: Наукова думка, 1986.

[9] Панарин А.С. Смысл истории // Вопросы философии. - 1999.№ 9. - C. 3-21.

[10] Постмодернизм и культура: Материалы «круглого стола» // Вопросы философии. - 1993. - № 3. - С. 3-16.

[11] Рабинович В.Л. Урок Августина: жизнь - текст // Августин Аврелий. Исповедь. - М.: Республика, 1992. - С. 223-258.

[12] Философский энциклопедический словарь / Гл.ред.: Л.Ф.Ильичев, П.А.Федосеев и др.-М.: Сов. энциклопедия, 1983 .

[13] Шевченко И.В. «Жизненный мир» и «Мир жизненной культуры» как бытийно-смысловое полагание идеи гармонии // Актуальні проблеми духовності. - Зб. наукових праць / Відп. ред. Я.В. Шрамко. - Кривий Ріг: Видавничий дім, 2006. - Вип. 7.- С. 427435. 